TREINAMENTO DE HABILIDADES SOCIAIS EM

CRIANÇAS EM UM CENTRO DE REFERÊNCIA

EM ASSISTÊNCIA SOCIAL

\title{
SOCIAL SKILLS TRAINING IN CHILDREN AT A \\ SOCIAL ASSISTANCE REFERENCE CENTER
}

\author{
Núbia Consuêlo T. Oliveira ${ }^{1}$ \\ Sheila Giardini Murta ${ }^{2}$ \\ Mariana Paula Silva ${ }^{3}$
}

Resumo: Este artigo descreve tratégia para prevenção e redução um treinamento em habilidades aos fatores de risco na infância.

sociais em crianças em situação

de vulnerabilidade social. Participaram 13 crianças, de 7 a 12

Palavras-chave: prevenção; anos, vinculadas ao Centro de vulnerabilidade social; habilidaReferência em Assistência Social des sociais; Centro de Referência (CRAS). As crianças participaem Assistência Social.

ram de 11 sessões e seus pais, de

Abstract: This article describes 2 sessões, todas com duração de training in social skills for chil90 minutos. É discutida a inserdren in situations of social vulção de treinamento em habilidanerability. 13 children participades sociais nos CRAS como ested, aged 7 to 12 years, linked to

\footnotetext{
$1 \quad$ Universidade Católica de Goiás

2 Universidade Católica de Goiás

3 Centro de Referência em Assistência Social
}

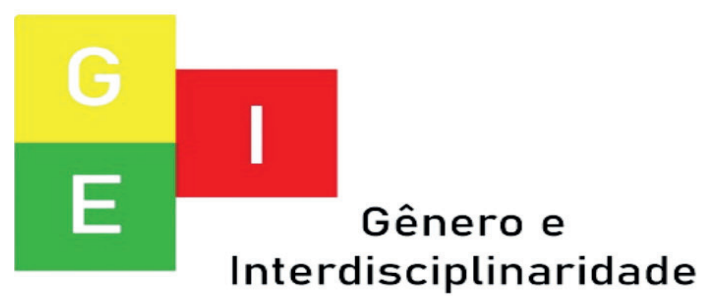


ISSN: 2675-7451

Vol. 03 - n 01 - ano 2022

Editora Acadêmica Periodicojs

the Social Assistance Reference Center (CRAS). The children participated in 11 sessions and their parents in 2 sessions, all lasting 90 minutes. GThe inclusion of social skills training in CRAS as a strategy for preventing and reducing risk factors in childhood is discussed.

Keywords: prevention; social vulnerability; social skills; Social Assistance Reference Center.

As políticas públicas em assistência social têm sido fortalecidas no Brasil com a implementação do Sistema Único de Assistência Social (SUAS), desde ano.... Inspirado no Sistema Único de Saúde (SUS), o SUAS compreende programas de alta complexidade, de média complexidade e de proteção social básica. Seu principal programa de proteção social básica é o Progra- ma de Atenção Integral à Família, cujos objetivos são fortalecer vínculos familiares e sociais, com vistas ao aumento da proteção e a redução de situações de risco. Destina-se a famílias em situação de vulnerabilidade social, decorrente da pobreza, carência e fragilização de vínculos afetivos - relacionais e de pertencimento social. O Programa conta com a atuação de assistentes sociais e psicólogos para o atendimento das famílias beneficiárias do PAIF no território de abrangência do CRAS (Centro de Referência de Assistência Social), também conhecido como Casa da Família (Secretaria Nacional de Assistência Social, 2005).

O PETI é um programa que propõe extinguir o trabalho infantil. Recebe crianças na faixa etária entre sete e 14 anos, permitindo a ascensão e a permanência da criança na escola.

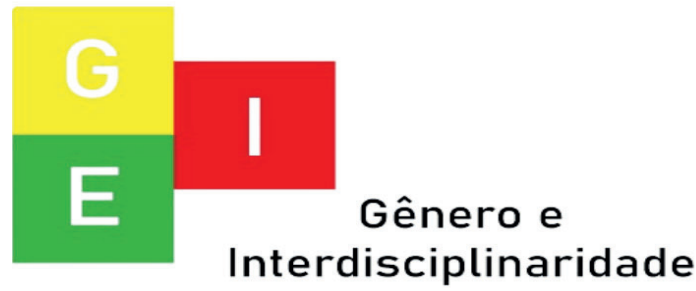


Vol. 03 - n 01 - ano 2022

Editora Acadêmica Periodicojs

Concede uma complementação de renda Bolsa Criança Cidadã; Proporciona apoio e orientação às famílias beneficiadas. Destina-se, prioritariamente, às famílias atingidas pela pobreza e pela exclusão social (Ministério do Desenvolvimento Social e Combate à Fome, 2007).

A terceira infância (7 a 12 anos) é um período do desenvolvimento humano marcado por uma série de influências. Nesta fase, todos os aspectos do desenvolvimento, sejam eles cognitivos, físicos, emocionais ou sociais, afetam e são afetados por características pessoais, contextuais e culturais (Papalia \& Olds, 2000). Para que a criança tenha um desenvolvimento saudável, é fundamental que ela viva num espaço em que receba acompanhamento necessário de acordo com cada faixa etária. A família é a instituição privilegiada para promover condições favoráveis para o desenvolvimento da criança (Gomide, 2004; Santos \& Marturano, 1999). É a partir dessa fase que as crianças começam a ter uma convivência social mais ampla: família, escola e grupos. A sociabilidade é fator primordial nas relações que tem seu início na infância e perdura por toda vida.

Existem eventos que são fatores de risco para a criança, como: regras sociais contraditórias, convivência com diferentes valores, deparar-se constantemente com uma realidade violenta transmitida pelos meios de comunicação (Del Prette \& Del Prette, 2006), nascimentos em famílias monoparentais, nascimentos decorrentes de gravidez na adolescência, maus tratos na família, divórcio dos pais, abuso de substâncias na família, perdas significativas, problemas de

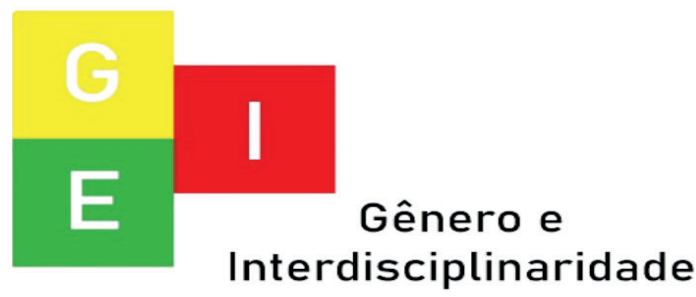


ISSN: 2675-7451

Vol. 03 - n 01 - ano 2022

Editora Acadêmica Periodicojs

aprendizagem, depressão, ansiedade, estresse, violência na comunidade e pobreza extrema (Murta, 2007; Mash \& Graham, 2005; Baraldi \& Silvares 2003; Sapienza \& Pedromônico, 2005). Dependendo do impacto, os fatores de risco podem trazer resultados negativos que prejudicam o desenvolvimento do indivíduo. São denominadas vulneráveis as crianças que são suscetíveis a tais fatores, ou seja, estas crianças estão mais propensas a desenvolver distúrbios evolutivos, problemas de conduta, desequilíbrio emocional e abuso de drogas na adolescência (Marsh \& Graham 2005, Pesce, Assis, Santos \& Oliveira, 2004; Ferreira \& Marturano, 2002).

Por outro lado, existem fatores ou mecanismos de proteção individuais, familiares e sociais para tornar inertes os eventos estressores, isentando o indivíduo dos fatores de risco (Grotberg, 2005). São apontados como fatores de proteção: apoio social, auto-estima positiva, estabilidade familiar, bom relacionamento com pessoas significativas, (Pesce \& Cols, 2004; De Antoni \& Koller, 2001) e competência intelectual (Dell'Aglio \& Hutz, 2004). Esses fatores de proteção podem estar em constante interação e vão mudando de acordo com as etapas do desenvolvimento humano.

A sintonia entre esses diversos fatores de proteção diante de situações de risco promove a resiliência. (Haggerty \& Cols, 2000, citado por Sapienza \& Pedromônico, 2005). Resiliência é a capacidade que o ser humano adquire para encarar e superar as adversidades. É um processo que visa o bem-estar e a qualidade de vida do indivíduo, sem que haja danos a outros seres

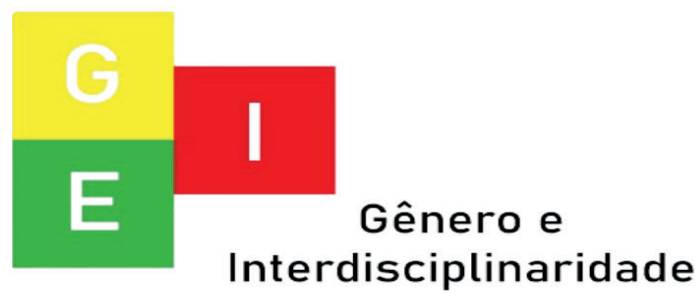


Vol. 03 - n 01 - ano 2022

Editora Acadêmica Periodicojs

(Grotberg, 2005). Infante (2005)

afirma que para ser resiliente um indivíduo deve viver ou passar por situações de vulnerabilidade e mostrar-se ajustado às expectativas sociais a suas etapas do ciclo vital.

Diante de inúmeros riscos e transtornos, de acordo com Murta (2007), programas preventivos são necessários. Estes podem ser voltados para a diminuição de episódios futuros de problemas de ajustamento, além da promoção de competências para beneficiar a saúde em cada etapa da vida.

Os programas preventivos podem ter diferentes objetivos referentes à redução dos eventos estressores, como comportamentos anti-sociais e abuso de drogas, ou referentes ao acréscimo de competências, como vínculo afetivo com os cuidadores, práticas educativas parentais saudáveis e habilidades sociais (Murta, 2007). Habilidades Sociais representam o conjunto de comportamentos de um indivíduo de acordo com a situação, levando em consideração a cultura na qual o indivíduo está inserido (Del Prette \& Del Prette, 1999). Caballo (2003) considera que "o comportamento socialmente hábil é esse conjunto de comportamentos emitidos por um indivíduo em um contexto interpessoal que expressa sentimentos, atitudes, desejos, opiniões ou direitos desse indivíduo de modo adequado à situação, respeitando esses comportamentos nos demais, e que geralmente resolve os problemas imediatos da situação enquanto minimiza a probabilidade de futuros problemas" (p. 6).

O Treinamento de Habilidades Sociais (THS) se dá a partir do momento em que se identifica a inadequação em uma

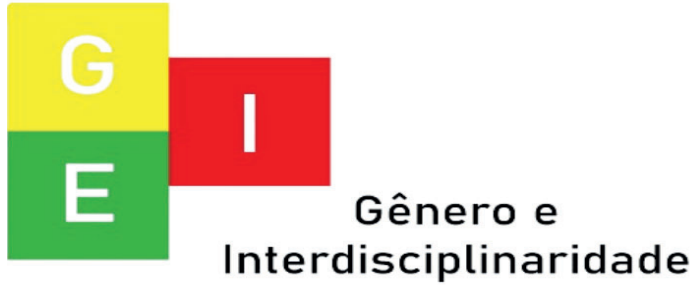


ISSN: 2675-7451

Vol. 03 - n 01 - ano 2022

Editora Acadêmica Periodicojs

ou mais habilidades da criança em seu repertório social. Segundo Caballo (1997), os seres humanos são "animais sociais", assim as HS são necessárias para as relações interpessoais. HS competentes determinam o presente e previne o futuro social e profissional do ser humano. Del Prette e Del Prette (2006) propõem um sistema de sete classes de Habilidades Sociais, como relevantes no desenvolvimento interpessoal da criança: autocontrole e expressividade emocional, civilidade, empatia, assertividade, fazer amizades, solução de problemas interpessoais e habilidades sociais acadêmicas. Os procedimentos empregados geralmente são embasados nas abordagens comportamentais e cognitivas; entre as técnicas mais usadas estão: contrato comportamental, reforçamento diferencial, modelagem, desempenho de papéis, ensaio comportamental, feedback, discriminação, tarefas de casa e relaxamento, além dos recursos pedagógicos, como exposição oral, questionamento reflexivo, atividades lápis-papel, histórias, desenhos e outros tipos de ilustração.

Existem no Brasil alguns estudos voltados para a prevenção e promoção do desenvolvimento saudável em situação de risco para a população infanto-juvenil. Baraldi e Silvares (2003) realizaram um trabalho de avaliação de um Programa de intervenção clínica comportamental, conjugado para pais e crianças com problemas de agressividade. Participaram do programa 16 crianças com idades entre seis e 10 anos, com suas mães, distribuídas em dois grupos: $1^{\mathrm{o}}$ grupo (Grupo Experimental), com nove crianças e o $2^{\circ}$ grupo (Grupo de Controle), com sete crian-

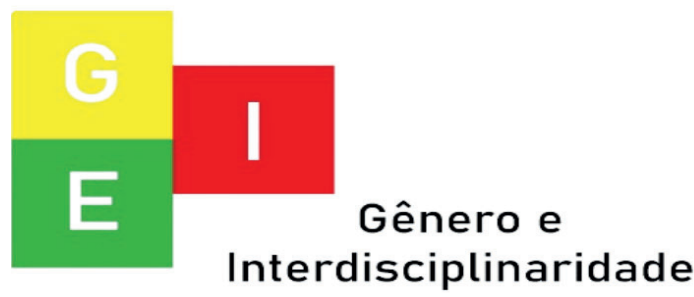


ISSN: 2675-7451

Vol. 03 - n 01 - ano 2022

Editora Acadêmica Periodicojs

ças. Efetivamente, participaram

do início ao fim do atendimento cinco díades do $1^{\mathrm{o}}$ grupo e quatro do $2^{\circ}$ grupo. $\mathrm{O}$ atendimento acontecia uma vez por semana, com duração de cinqüenta minutos em grupo terapêutico seguido de espera recreativa, enquanto as mães eram atendidas. O Programa contou com 15 sessões para o $1^{\circ}$ grupo e 24 para o segundo grupo. Os escores apontaram que tratamentos que abrangem os pais e as crianças conseguem melhor resultado na evolução da qualidade das relações entre eles e aprimoram significativamente o comportamento da criança. Segundo a percepção das mães que participaram, o $1^{\mathrm{o}}$ grupo obteve melhor resultado em relação ao $2^{\circ}$ grupo. Este se tratava de mães extremamente estressadas, passando por momentos pessoais críticos, ao passo que não conseguiam controlar suas emoções.
Assim o trabalho conclui que os estressores externos podem ter influenciado o desempenho do grupo.

Atualmente, existem vários programas sociais dirigidos à classe infanto-juvenil, tais como Programa de Atenção Integral à Família (PAIF) e Programa de Erradicação do Trabalho Infantil (PETI). O PAIF é um programa de Proteção Social Básica, do Sistema Único de Assistência Social (SUAS) que desenvolve ações socializadoras. Tem a perspectiva de fortalecer vínculos familiares e sociais. É um trabalho voltado para o aumento da proteção e a redução de situações de risco. Destina-se a famílias em situação de vulnerabilidade social, decorrente da pobreza, carência e fragilização de vínculos afetivos - relacionais e de pertencimento social. O Programa conta com a atuação de assistentes sociais

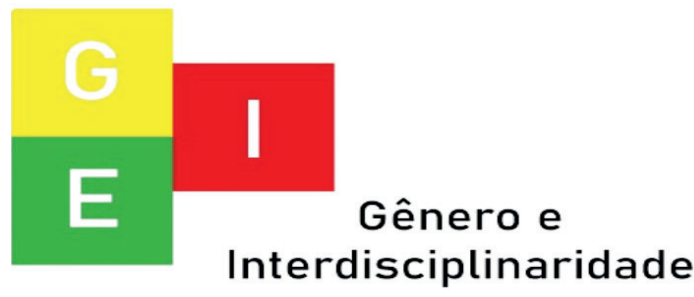


ISSN: 2675-7451

Vol. 03 - n 01 - ano 2022

Editora Acadêmica Periodicojs

e psicólogos para o atendimento das famílias beneficiárias do PAIF no território de abrangência do CRAS (Centro de Referência de Assistência Social), também conhecido como Casa da Família (Secretaria Nacional de Assistência Social, 2005).

O PETI é um programa que propõe extinguir o trabalho infantil. Recebe crianças na faixa etária entre sete e 14 anos, permitindo a ascensão e a permanência da criança na escola. Concede uma complementação de renda Bolsa Criança Cidadã; Proporciona apoio e orientação às famílias beneficiadas. Destina-se, prioritariamente, às famílias atingidas pela pobreza e pela exclusão social (Ministério do Desenvolvimento Social e Combate à Fome, 2007).

Em Jandaia - GO, dois Programas de Treinamento de Habilidades Sociais foram reali- zados através do PAIF. Os estudos foram realizados no PETI, com intuito de funcionar como fator de proteção a comportamentos de risco, sendo um deles voltado à promoção de resiliência. Ambos realizados 11 sessões psicoeducativas com adolescentes de 11 a 15 anos e três encontros quinzenais com os pais para discussão de estabelecimento de limites, expressão de afeto, habilidades comunicativas e autonomia. O primeiro trabalho (Silva, 2006), descreveu a avaliação de processo de Programas de HS no que se refere a fontes de satisfação e insatisfação dos participantes quanto a intervenção e ao alcance de metas intermediárias. Teve como temas auto-estima, auto-eficácia, fazer amizades, motivação, expressar sentimentos. Foram utilizadas como técnicas dramatização, relaxamento e treino de habilidades sociais. Os

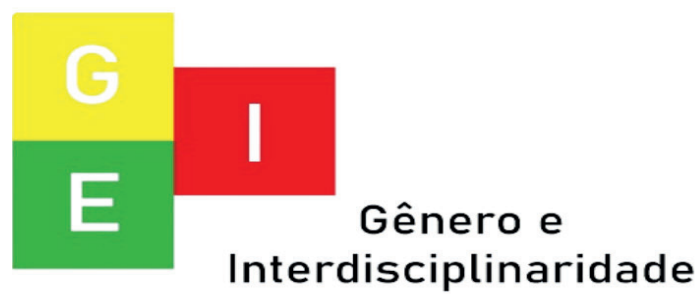


Vol. 03 - n 01 - ano 2022

Editora Acadêmica Periodicojs

resultados, coletados através de checklist de HS, roteiro de entrevista com os pais, baralho de sentimentos e relato dos adolescentes divididos em duas categorias: sentimentos relativos à satisfação na sessão (sentimentos e estados emocionais vivenciados durante a sessão) e efeitos percebidos como derivados da intervenção (mudanças de pensamento e crenças modificadas no decorrer das sessões), mostram que a intervenção alcançou os objetivos almejados quando avalia a presença de bem-estar, liberdade de expressão e aprendizagem de habilidades sociais. Todas as metas intermediárias estabelecidas ocorreram no decorrer das sessões, algumas com maior freqüência que outras. O segundo trabalho (Vaz, 2007) teve por objetivo promover o aumento das habilidades sociais e o desenvolvimento do potencial de resiliência. Os temas trabalhados foram auto-estima, fazer amizades, resiliência, família, cidadania e assertividade. As técnicas utilizadas foram dramatizações, vivências grupais, fornecimento de instruções e reestruturação cognitiva. Para verificar a reação dos adolescentes, foi utilizado o "baralho de sentimento" para relatos verbais com análise dos conteúdos e uma escala para medir o nível de resiliência. O trabalho demonstrou ganhos em habilidades sociais comportamentais e sócio-cognitivas, promovendo aumento no potencial de resiliência.

Diante do exposto, considera-se que o desenvolvimento infantil é uma etapa importante para o desenvolvimento posterior. Considera-se ainda que a vulnerabilidade seja um fator desencadeador de riscos, que pode impedir o desenvolvimento saudável e gerar transtornos futuros.

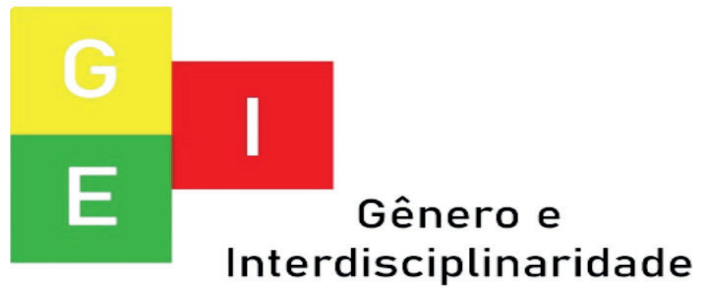


Vol. 03 - n 01 - ano 2022

Editora Acadêmica Periodicojs

Daí nasce o desejo de realizar este estudo com crianças atendidas pelo PETI, dando continuidade aos trabalhos de Silva (2006) e Vaz (2007).

Assim, o presente trabalho tem como objetivo promover o aumento de habilidades sociais em um grupo de crianças.

\section{Método}

\section{Participantes}

Os participantes foram aproximadamente 13 crianças de ambos os sexos, atendidas pelo PETI, no turno vespertino de Jandaia - GO. Os critérios de inclusão no programa foram crianças na terceira infância (7 a 12 anos), freqüentes no PETI e com desejo de participar voluntariamente do programa.

\section{Ambiente, Material e Instru- mentos}

As sessões aconteceram

em uma sala do PETI, com mesa, cadeiras, carteiras e armários. Foram usados durante as intervenções materiais de consumo, tais como lápis de cor, folhas de chamex, tinta, cartolina, pincéis, esparadrapo, gases, etc. além de materiais permanentes como aparelho de som, CD's e câmera fotográfica.

Os Instrumentos para avaliação das sessões foram:

Baralho de sentimentos: consiste em várias cartas, cada uma com a expressão de um sentimento diferente, ex. alegria, raiva e vergonha (Murta, 2008).

Cartões coloridos: adaptado da técnica "Os sentimentos tem cores", (Del Prette \& Del Prette, 2006), para identificação e nomeação de sentimentos. As crianças usavam estes cartões

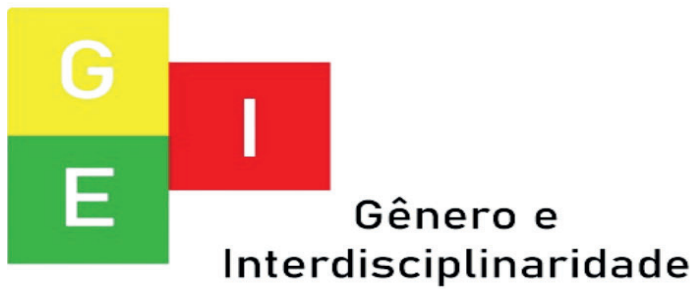


Vol. 03 - n 01 - ano 2022

Editora Acadêmica Periodicojs

para marcar, a cada intervenção, ao lado de seu nome em um cartaz, a cor que indica seu sentimento, de acordo com a sessão trabalhada.

Os Instrumentos para avaliação de resultados foram:

Checklist das Habilidades Sociais relevantes: o checklist é de autoria de Magalhães (2002) e apresenta uma lista de comportamentos, por exemplo “nomeia emoções" e "cumprimenta pessoas", cuja ocorrência durante a sessão deve ser assinalada na linha correspondente a cada comportamento.

Roteiro de entrevista com os pais: roteiro de autoria de Silva (2006) consiste em cinco perguntas dirigidas aos pais relativas às modificações e efeitos da intervenção no comportamento de seus filhos após intervenção. Exemplo: Você pai e/ou mãe per- cebeu alguma mudança de comportamento significativa em seu filho após o grupo de crianças?

Sociometria por indicação (Anexo A): consiste da coleta de informações sobre os tipos e qualidades do relacionamento social de uma pessoa com seu grupo de companheiros. Cada criança escreve do grupo de colegas, o nome de três com quem ela mais gosta ou menos gosta para brincar (Coie, Dodge \& Coppotelli, 1982).

Caderno para observação de comportamentos: foi usado para registro de desempenhos verbais, não-verbais, paralingüísticos e a capacidade da criança em reagir às demandas do ambiente no momento adequado.

Questionário de relações interpessoais na escola: objetiva conhecer através da percepção do monitor a freqüência que ocorrem os conflitos inter-

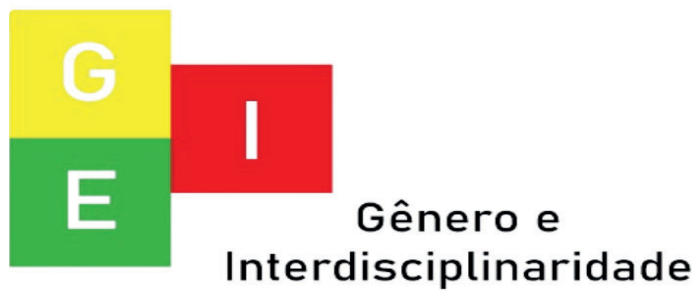


ISSN: 2675-7451

Vol. 03 - n 01 - ano 2022

Editora Acadêmica Periodicojs

pessoais listados em uma semana na sala que continha 11 itens descritivos de conflitos. Exemplo: Aluno recusa-se a devolver material emprestado que outro lhe pede e Aluno grita e xinga o colega (Del Prette \& Del Prette, 2003).

\section{Procedimentos}

O programa aconteceu em 11 sessões, com duração de 90 minutos para as crianças e 2 reuniões com os pais, com duração de 90 minutos.

A comunicação do trabalho para as crianças ocorreu uma semana antes do primeiro encontro, com apresentação da estagiária e duas psicólogas do PAIF. Foi entregue bilhete- convite aos pais para que comparecessem à reunião no PETI para esclarecimento do trabalho e assinatura do Termo de Consenti- mento Livre e Esclarecido.

\section{Intervenção}

Primeiro encontro teve como objetivos realizar a apresentação dos participantes, das facilitadoras, da finalidade da pesquisa e o estabelecimento do contrato de trabalho (dia, horário e $\mathrm{n}^{0}$ de sessões). Esta sessão visava promover a integração do grupo e minimizar as possíveis resistências de participação.

\section{Segundo encontro -}

teve como finalidade fortalecer o contrato estabelecido no primeiro encontro através da construção de uma Lista de Boa Convivência, em que as crianças falavam comportamentos que seriam permitidos no grupo e a estagiária escrevia em uma cartolina em forma de cartaz. Em seguida, em outra cartolina escrevia comportamentos que eram proibidos no

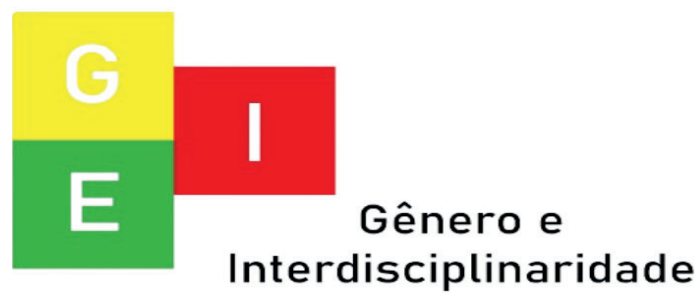


Vol. 03 - n 01 - ano 2022

Editora Acadêmica Periodicojs

grupo seguindo o mesmo padrão anterior. Logo foram dados a cada criança dois cartões, sendo um amarelo e outro vermelho, com os quais iriam advertir o colega de acordo com a gravidade do comportamento, como num jogo de futebol. Esta sessão teve ainda o intuito de promover o autoconhecimento e auto-revelação das emoções, em que foi proposto às crianças que construíssem uma máscara de sua própria face, representando o modo em que se apresentavam naquele momento. Depois da construção da máscara, as crianças foram convidadas a relatar suas emoções descritas na máscara.

Terceiro encontro teve a intenção de melhorar o exercício de comunicação e demonstração de boas maneiras. Utilizou-se o texto de apoio "A importância da convivência" como leitura antecedente à folha de exercício da vivência "Palavras Mágicas" (Del Prette e Del Prette, 2006). As crianças escreviam nas lacunas das orações palavras como "por favor", "obrigado(a)". Durante o exercício, usou-se de estímulo individual “muito bem!"; "Isso mesmo!"; “Está certo!". Em seguida para melhor memorização foi dada cópia e cantada várias vezes a música "Palavras Mágicas - Eliana". A sessão foi finalizada com a entrega de uma folha contendo a escrita de algumas Palavras Mágicas como sugestão de que as crianças pregassem na parede do quarto. Como tarefa de casa solicitou-se às crianças que fizessem uso durante a semana das palavras aprendidas. Para avaliar a reação das crianças à sessão, foi utilizada a técnica do Baralho de Sentimentos.

\section{Quarto encontro -} consistiu em aplicar a Avaliação

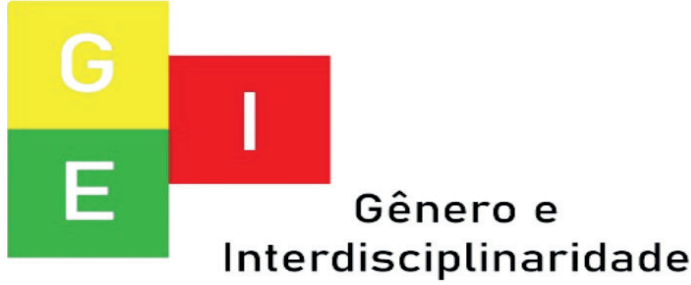


ISSN: $2675-7451$

Vol. 03 - n 01 - ano 2022

Editora Acadêmica Periodicojs

Sociométrica de indicação (Del se como o corpo reagia quando Prette e Del Prette, 2006), com estava com aquele sentimento. o objetivo de coletar dados sobre Em seguida, sugeriu-se que cada os tipos e qualidade do relacionamento social de cada criança criança contasse uma situação que produzia aquele sentimento em particular com o grupo. Em e demonstrasse com a expressão seguida, foram trabalhadas duas vivências objetivadas na decodificação das emoções, o autocontrole e a conveniência de expressão ou não. Sendo que a primeira delas mostrou-se uma caixa de papelão fechada, escrito em letras grandes "Caixinha de..." (e um traço para completar), instigou-se as crianças a ler o que estava escrito. Narrou-se a história "A Caixa de Pandora" (Del Prette e Del Prette, 2006), intercalando-a com algumas perguntas indicadas no texto. Ao final da história completou-se o nome da “Caixinha de Sentimentos". E assim como na narração, abriu-se a caixa e pediu-se que cada criança retirasse um papel e descrevesdo rosto, gestos e ou posição do corpo o sentimento que retirou da caixa, para que o restante do grupo adivinhasse. Como tarefa de casa solicitou-se que cada criança observasse os sentimentos que lhes apareciam nas mais variadas circunstâncias e anotassem.

Quinto encontro - teve os mesmos objetivos do quarto encontro. Identificar, nomear e controlar sentimentos. Deu-se as crianças uma ficha "Os Sentimentos Tem Cores" (Del Prette e Del Prette, 2006), com seis desenhos de pessoas expressando diferentes sentimentos (medo, tristeza, alegria, vergonha, raiva, desânimo), onde cada figura tinha uma linha para colorir a cor

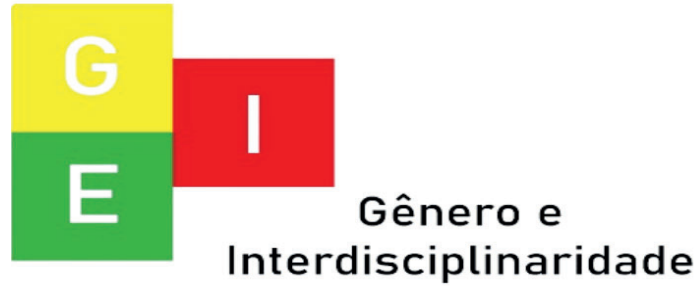


ISSN: 2675-7451

Vol. 03 - n 01 - ano 2022

Editora Acadêmica Periodicojs

do sentimento expresso na figura e seis lápis de cor iguais para cada criança. Determinou-se como tarefa de casa prestar atenção nos sentimentos marcantes em cada dia da semana e escrevê-los, em seguida, pintura de onde se localizava este sentimento na figura do corpo humano que receberam. Para avaliar a reação das crianças à sessão, foi utilizada a técnica do Baralho de Sentimentos.

Sexto encontro - foi proposto que as crianças relatassem a experiência que tiveram com a tarefa de casa. Em seguida, apresentou-se, em cartaz, a cor predominante atribuída pelas crianças a cada sentimento e suas respectivas cores, de acordo com o quinto encontro e discutiu-se com as mesmas o significado de dar cores aos sentimentos. A sessão teve o objetivo de levar as crianças à reflexão sobre o sentimento de gostar, a relação sentimentos/ações e exercício de expressão de sentimentos através da vivência "Gostando dos Colegas" (Del Prette e Del Prette, 2006). Para a vivência discorreu-se sobre o gostar através do texto de apoio "O Gostar ativo". Em seguida perguntou-se às crianças se sabiam alguma maneira para tornar visível o gostar. Então mostrou-se um cartaz com cinco maneiras de expressão do gostar. Cada membro falou qual era a maneira mais fácil e a mais difícil para si de expressão. Após a discussão entregou-se a cada participante uma folha de papel para confecção de um desenho, música ou poesia com nome de um colega do grupo, escolhido em caixa de sorteio com todos os nomes. As próprias crianças entregaram o desenho ao colega e logo afixou-se em exposição na sala, intitulado "Lembrança para meu amigo". Para finalizar, fixou-se

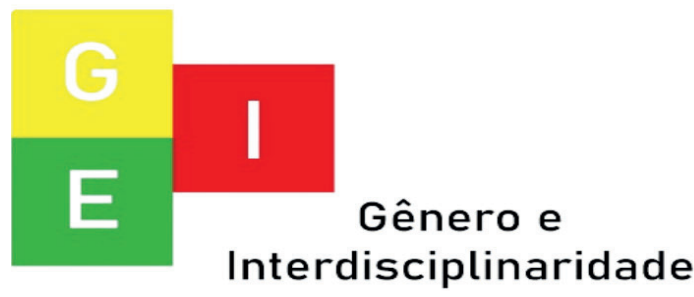


ISSN: 2675-7451

Vol. 03 - n 01 - ano 2022

Editora Acadêmica Periodicojs

um cartaz na parede com os nomes de cada participante e pediu-se que cada criança marcasse, ao lado de seu nome, com cartões coloridos, a cor indicativa de seu sentimento. A solicitação da tarefa de casa foi que cada membro confeccionasse um presente para um amigo da sala; e foi pedido que cada criança trouxesse para a próxima sessão fotografias de si com a família.

Sétimo encontro - objetivou trabalhar as relações familiares, com a intenção de conhecer e dividir com o grupo a estrutura e dinâmica familiar de cada uma das crianças. Baseado na atividade "Quando eu..." (Virgolim, Fleith \& Pereira, 1999), na qual as crianças deveriam completar frases do tipo: quando eu era criança... meus melhores amigos... meus pais... a minha família... o que eu mais queria era... etc.; seguindo algu- mas perguntas: "Quem são as pessoas da fotografia?", "Qual a melhor lembrança da infância?", "Se você pudesse mudar algo em sua vida, o que mudaria?". Como tarefa de casa, solicitou-se que as crianças observassem e registrassem durante a semana todos os momentos em que os pais tinham comportamentos que as crianças achavam inadequados e o que as crianças ou outras pessoas faziam antes e depois destes comportamentos deles (Weber, 2007). Como avaliação da sessão foi utilizado os cartões de cores com explicação das crianças do porque escolhiam este determinado cartão.

Oitavo encontro - teve

o mesmo objetivo do encontro anterior. Deu-se uma folha de papel para que os participantes anotassem alguns comportamentos dos pais, os quais gostariam que fossem mudados. Em segui-

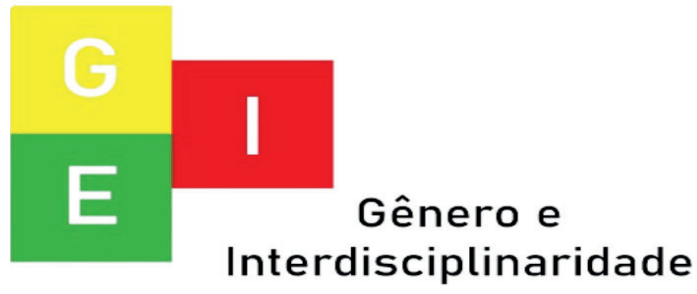


Vol. 03 - n 01 - ano 2022

Editora Acadêmica Periodicojs

da, abriu-se espaço para que as crianças falassem sobre o assunto. Nesse encontro relembrou-se todos os temas trabalhados. A tarefa de casa foi exercitar as questões até então trabalhadas. A avaliação foi feita através do cartão de cores, com relato verbal do porque da escolha do cartão.

Nono encontro - teve

o intuito de promover habilidades assertivas que permitisse às crianças aprender a enfrentar as mais diversas situações, com domínio da ansiedade e demonstração adequada dos sentimentos, desejos e opiniões. Deu-se às crianças duas folhas com situações especificas (Del Prette \& Del Prette, 2005), em que uma criança diante de uma determinada situação poderia apresentar três reações diferentes: agressiva, passiva ou assertiva. As crianças deveriam pintar a reação assertiva de cada situação. Questio- nou-se uma situação de cada vez, com uma roda de debate. Como tarefa de casa entregou-se duas outras folhas, com duas novas situações, para que cada criança refletisse sua reação e pintasse a reação assertiva. A sessão foi encerrada com a avaliação através dos cartões coloridos.

\section{Décimo encontro -}

teve como objetivo trabalhar a compreensão, solidariedade, empatia, atenção, observação e o reconhecimento dos sentimentos dos colegas. O trabalho foi feito através da vivência "Olhando e ajudando" (Del Prette e Del Prette, 2006). A sala foi previamente arrumada, com três cadeiras em destaque de frente para o grupo. Duas crianças previamente orientadas para chegarem um pouco atrasadas: a primeira com um "curativo" na testa, comportando-se como pessoa ferida e a segunda criança foi orientada

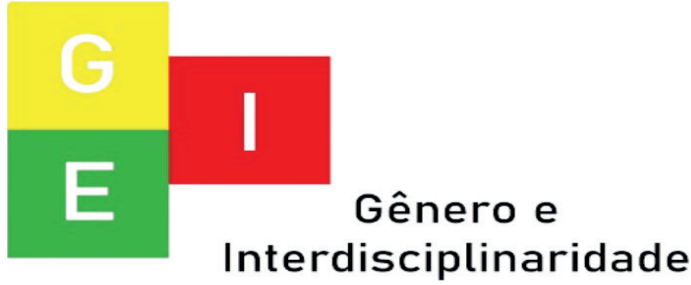


ISSN: 2675-7451

Vol. 03 - n 01 - ano 2022

Editora Acadêmica Periodicojs

a manter uma das mãos sobre a barriga, com expressão e postura de dor. Fingiu-se explicar outra atividade, chamando três crianças para sentar nas cadeiras colocadas à frente, logo as crianças "ferida" e "enferma" se aproximaram, totalizando cinco crianças à frente do grupo. Continuou-se a explicação da atividade, ao mesmo tempo, observou-se com discrição o que se passava. Logo ocorreram tentativas de auxílio aos colegas. Criou-se um debate em cima das possibilidades de ajuda que poderia ser dada aos “enfermos”. A sessão finalizou com a avaliação através dos cartões coloridos.

Décimo primeiro encontro - teve a finalidade de estimular o uso de estratégias saudáveis de enfrentamento diante de uma situação, a experimentação da auto-revelação e o autocontrole, através da respi- ração diafragmática. Propôs-se às crianças para que deitassem no chão, adotassem uma posição cômoda e respirassem lenta e profundamente: inspirando como se estivesse enchendo um balão na barriga e expirando como se estivesse soprando uma vela. Apresentou-se às crianças que este tipo de respiração profunda pode ser feita sempre que quiser diminuir a tensão, o choro, a ansiedade, o cansaço ou qualquer reação emocional desagradável. Aplicou-se a Avaliação Sociométrica com o objetivo de comparar com os dados já coletados na quarta sessão. Logo em seguida, fez-se um círculo, onde todas as crianças tiveram a oportunidade de falar sobre como se sentiram durante o relaxamento. Fez- se a avaliação da sessão com uso dos cartões coloridos.

\section{Análise dos Dados}

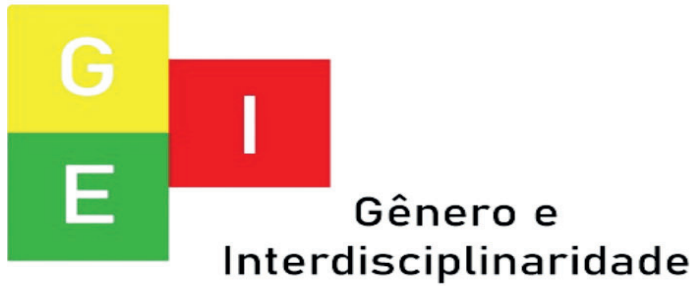


Vol. 03 - n 01 - ano 2022

Editora Acadêmica Periodicojs

bais coletados a respeito das ha-

Durante todos os encontros de intervenção, a facilitadora observou a ocorrência de habilidades sociais relevantes e preencheu, imediatamente após as sessões, o Checklist de Habilidades Sociais relevantes. Ao fim de cada encontro, as crianças foram convidadas a apresentar seu feedback com relatos de seus sentimentos relativos ao encontro do dia. Verificou-se os relatos através do baralho de sentimentos no terceiro, quarto e quinto encontro, após usou-se os cartões coloridos. Aplicou-se o Questionário de Relações Interpessoais na Escola no monitor deste grupo, antes e após o programa de intervenção. Ao término da intervenção com as crianças, visitou-se os pais para entrevista com intuito de avaliar as mudanças percebidas em seus filhos.

A análise de dados ver- bilidades interpessoais das crianças foi feita através de análise de conteúdo.

Foi feito ainda, avaliação sociométrica no quarto e décimo primeiro encontro. Computou-se o escore, com base na quantidade de escolhas que cada criança recebe, de impacto e de preferência social.

\section{Resultados}

Por meio de um Checklist de Habilidades Sociais relevantes observou-se a ocorrência de quatro, das sete classes de habilidades sociais, entendidas como prioritárias no desenvolvimento interpessoal da criança, segundo Del Prette \& Del Prette (2006). Como mostra a Tabela 1, todas as habilidades descritas ocorreram durante o programa. As habilidades: controla

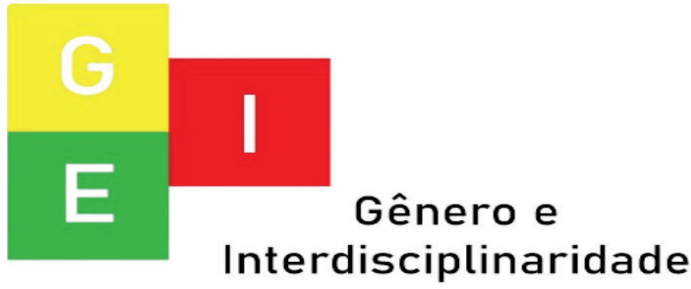


ISSN: $2675-7451$

Vol. 03 - n 01 - ano 2022

Editora Acadêmica Periodicojs

raiva/expressa raiva assertiva- pessoas, usa locuções, faz elo-

mente, segue regras, presta aten-

ção no outro mantendo contato

visual, respeita as diferenças,

oferece ajuda ao próximo, fala

sobre as próprias qualidades e

defeitos, concorda/discorda de

opiniões, lida com críticas e go-

zações, pede mudança de com-

portamento e identifica e avalia

possíveis alternativas de solução,

tiveram um número menor de

ocorrência. Já as habilidades: no-

meia emoções, nomeia emoções

dos outros, consegue falar sobre

seus sentimentos, cumprimenta gios, faz perguntas, chama o ou-

tro pelo nome, responde pergun-

tas e expressa agrado, tiveram

um número maior de ocorrência.

A Tabela 2 apresenta a freqüência em que ocorreram alguns conflitos interpessoais entre as crianças durante a primeira e última semana de intervenção, segundo a percepção do monitor. Observa-se que todos os comportamentos diminuíram ou extinguiram, comparando a primeira e a décima primeira intervenção.

Tabela 1. Ocorrência de HS entre os participantes observadas durante as intervenções*.

Habilidades sociais relevantes
Nomeia emoções
Nomeia emoções dos outros
Consegue falar sobre seus sentimentos
Controla raiva/ Expressa raiva assertivamente
Cumprimenta pessoas
Usa locuções como: por favor, obrigado, desculpe, com licença
Faz elogios
Aguarda a vez para falar
Faz perguntas
Chama o outro pelo nome
Segue regras
Presta atenção no outro mantendo contato visual
...


ISSN: $2675-7451$

Vol. 03 - n 01 - ano 2022

Editora Acadêmica Periodicojs

Respeita as diterenças

Oferece ajuda, coopera

Fala sobre as próprias qua

Concorda/ discorda de opiniões

Lida com críticas e gozações

Pede mudança de comportamento

Reconhece e nomeia diferentes tipos de problemas

Identifica e avalia possíveis alternativas de solução

Responde perguntas coerentemente

Expressa desagrado

Expressa agrado

Tabela 2. Freqüência de conflitos interpessoais em sala, ao início e fim das intervenções, na percepção do monitor.

\begin{tabular}{lcc}
\hline Conflitos interpessoais em sala de aula & $\begin{array}{c}\text { vezes/1 } \\
\text { semana }\end{array}$ & $\begin{array}{c}\text { vezes/11 } \\
\text { semana }\end{array}$ \\
\hline Aluno grita e xinga o colega & 50 & $2 / 3$ \\
Aluno ameaça a agredir fisicamente o outro & 15 & 0 \\
Aluno agride fisicamente (empurra, dá socos etc.) o colega & 10 & 0 \\
Aluno recusa-se a seguir instrução do professor & 5 & 1 \\
Aluno ironiza o professor & 5 & 0 \\
Aluno atira objetos (papel, borracha) em colegas & 5 & 0 \\
Alguns alunos entram em bate-boca perturbando o andamento da aula & 3 & $2 / 3$ \\
Mais de dois alunos brigam na sala de aula & 3 & 1 \\
Aluno grita com o professor & 3 & 0 \\
Aluno reclama providências do professor contra colega que o agrediu & 2 & 0 \\
Aluno recusa-se a devolver material emprestado que outro lhe pede & 0 & 0 \\
\hline
\end{tabular}

A análise da Avaliação

Sociométrica exposta na Tabela

3 evidenciou através da quan-

tidade de escolhas, o que cada

criança recebeu em termos de

aceitação-rejeição. De acordo

com Coie e colaboradores (1982)

nessa avaliação, as crianças po-

dem ocupar cinco tipos de status

sociométrico: (a) negligenciadas
- crianças com pouco envolvimento com companheiros, baixa assertividade e expressividade emocional; (b) rejeitadas - déficits em habilidades de civilidade e de convivência social; (c) populares - presença e coerência de comportamentos socialmente harmoniosos; (d) controvertidas - reações habilidosas alternadas

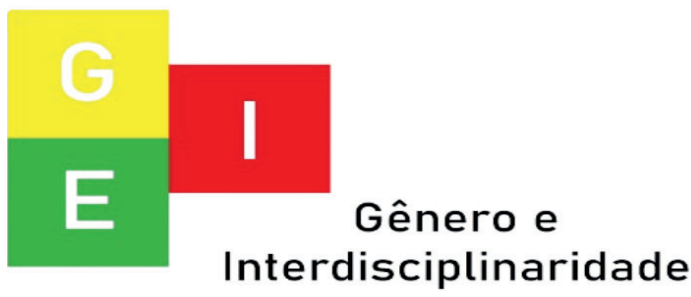


ISSN: 2675-7451

Vol. 03 - n 01 - ano 2022

Editora Acadêmica Periodicojs

com reações não-habilidosas e

(e) medianas - não adequam em

qualquer das categorização an-

tecedente e não são distinguidos

por seus comportamentos sociais

específicos.

Observa-se que oito

crianças diminuíram o número

de rejeição, duas mantiveram e uma criança aumentou o número

de rejeições. Esta criança que ao

início tinha duas rejeições e ao final da intervenção teve três rejeições. Apenas Samuel teve aumento de aceitação, comparando os números de início e final da intervenção.

Tabela 3. Índices de aceitação e rejeição pelos pares ao início e final da intervenção.

\begin{tabular}{lcccc}
\hline & \multicolumn{2}{c}{ Início } & \multicolumn{2}{c}{ Final } \\
\hline Participantes & $\begin{array}{c}\text { aceitação } \\
\text { (mais gosta) }\end{array}$ & $\begin{array}{c}\text { rejeição } \\
\text { (menos gosta) }\end{array}$ & $\begin{array}{c}\text { aceitação } \\
\text { (mais gosta) }\end{array}$ & $\begin{array}{c}\text { rejeição } \\
\text { (menos gosta) }\end{array}$ \\
\hline Maria & 9 & 2 & 0 & 0 \\
Joana & 5 & 2 & 3 & 1 \\
Marcela & 1 & 1 & 1 & 0 \\
João & 2 & 3 & 2 & 3 \\
Pedro & 2 & 8 & 1 & 5 \\
Adriane & 8 & 0 & 3 & 0 \\
Marcos & 2 & 3 & 0 & 0 \\
Samuel & 1 & 2 & 2 & 1 \\
Marcelo & 2 & 10 & 0 & 2 \\
Michelle & 4 & 2 & 4 & 0 \\
Caroline & 2 & 2 & 2 & 3 \\
Fabiana & 0 & 3 & 0 & 3 \\
Clara & 0 & 1 & 3 & 0 \\
\hline
\end{tabular}

Após a intervenção, dois casais, três mães e um pai foram entrevistados com a intenção de avaliar as modificações e efeitos da intervenção no comportamento de seus filhos. A análise dos relatos verbais revelou duas categorias de mudança de comportamento percebidas pelos pais, baseado no sistema de categorias que compreende habilidades sociais e desenvolvi-

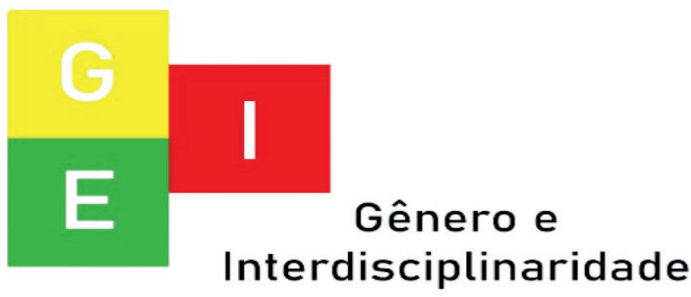


Vol. 03 - n 01 - ano 2022

Editora Acadêmica Periodicojs

mento acadêmico (Silva, 2006). to meu filho era calado, agora já A subcategoria habilidades so- chega em casa contando como ciais se subdivide em: "expres- foi na escola ou no passeio". A sar carinho" (03 relatos), "puxar subcategoria "expressar agrado e conversa" (02 relatos), "expressar desagrado", fica evidente na fala agrado e desagrado" (02 relatos), “diminuiu conflitos/agressão física" (02 relatos), "reconhece e nomeia probabilidades" (01 relato) e a categoria desempenho acadêmico foi definida como "melhora no desenvolvimento acadêmico quanto às notas e reclamações por parte dos professores" (03 relatos). Estes dados estão listados na tabela 4 .

A habilidade social que teve maior percepção por parte dos pais foi "expressar carinho" que pode ser ilustrada através dos relatos: "Ele chegou perto de mim e me deu um beijo, coisa que nunca tinha feito antes". O "puxar conversa" foi descrito por uma mãe, como revela a fala: "me sentia preocupada com o quan"Ele era tão calado que eu nunca sabia se ele estava gostando ou não de qualquer coisa, agora já diz quando quer ou não ir a um lugar com a gente". O “diminuiu as brigas" também ocorreu, na opinião de duas mães: "as brigas em casa, com a irmã diminuíram bastante e quando acontecem são menos violentas". E na subcategoria "reconhece e nomeia probabilidades" a mãe relata que: “Ele já aprendeu como proceder diante das situações, sabe o que é, mas ainda tem dificuldade de aplicá-las”. E por fim, quanto a categoria Desempenho Acadêmico, os pais relataram que houve melhora no desenvolvimento acadêmico quanto às notas $\mathrm{e}$ diminuíram as reclamações por

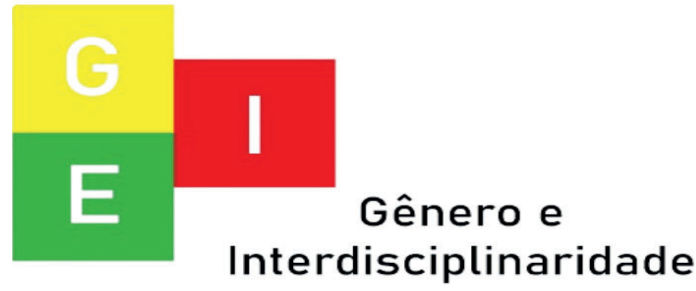


ISSN: $2675-7451$

Vol. 03 - n 01 - ano 2022

Editora Acadêmica Periodicojs

parte dos professores através das mais interessado na escola".

falas: "As notas na escola melho-

raram, o grupo ajudou, ele ficou

Tabela 4. Freqüência de ocorrência de habilidades sociais e de desempenho acadêmico na opinião dos pais após a intervenção.

\begin{tabular}{lc}
\hline \multicolumn{1}{c}{ Categorias } & Ocorrências \\
\hline Habilidades Sociais & \\
\hline Expressar carinho & 3 \\
Puxar conversa & 2 \\
Expressar agrado e desagrado & 2 \\
Diminuiu brigas & 2 \\
Reconhece e nomeia probabilidades & 1 \\
Total & 10 \\
Progresso no desempenho acadêmico & \\
Melhora no desenvolvimento acadêmico & 4 \\
Total & 4 \\
\hline
\end{tabular}

\section{Discussão}

O objetivo deste traba-

lho foi promover o aumento de habilidades sociais em um grupo de crianças. Os dados encontrados no presente estudo apontaram que os objetivos do programa em parte foram alcançados. Através da análise dos resultados pode-se concluir que as crianças apresentaram aumento significativo das habilidades sociais de civilidade, assertividade, autocon- trole e expressividade emocional

e empatia. Segundo Gorayeb

(2006) tanto as técnicas quanto

o trabalho de grupo, são instrumentos preciosos, pois promove o processo de obtenção e execução das habilidades. Em contrapartida, não foi possível desenvolver o trabalho com os pais. Foram apenas dois encontros com pais, que deixaram de acontecer em função do não comparecimento dos mesmos.

Houve uma percepção

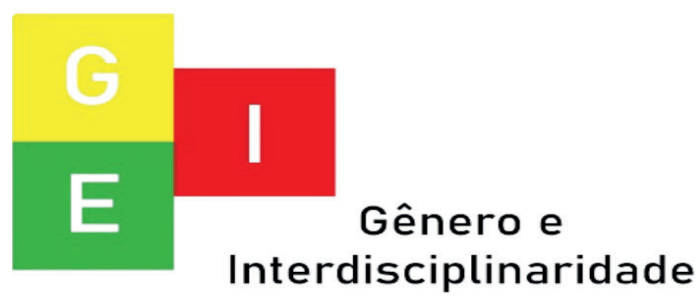


ISSN: 2675-7451

Vol. 03 - n 01 - ano 2022

Editora Acadêmica Periodicojs

positiva dos resultados do trabalho entre os vários informantes: pais, monitor, pares e terapeutas. O que aumenta a nossa confiança em dizer que o programa foi benéfico, e justifica sua replicação no PETI, tanto com as próprias crianças, quanto com seus monitores. Aliás, indica-se que o desenvolvimento de habilidades sociais faça parte do cronograma de trabalhos desenvolvidos pelos Programas Sociais. Segundo Sebastiani (2004), os programas psicoeducativos estimulam comportamentos saudáveis, desenvolvimento da autonomia e da cidadania, assim se torna fator de proteção diante das demandas do cotidiano. As intervenções de promoção de habilidades podem ter melhores resultados quando conjugada (pais e filhos). Confirmando achados em estudos anteriores (D'Avila-Bacarji, Marturano \& Elias, 2005; Ferreira \&
Marturano, 2002; Bolsoni-Silva \& Marturano, 2002), intervenções com pais são indispensáveis à prevenção e à redução de problemas de comportamento em crianças.

Os instrumentos usados para avaliação do Programa mostram a generalização de vários comportamentos das crianças em ambientes diversos. Entretanto, vale ressaltar que alguns comportamentos, como "seguir regras" e "aguardar a vez para falar", apareceram, mas não tiveram um número tão satisfatório como outros.

Os resultados referentes ao Checklist de Habilidades Sociais relevantes, mostram que todas as habilidades ocorreram. Contudo, "cumprimentar pessoas", "chamar pelo nome" e "expressa desagrado", ocorreram com maior freqüência. Isso provavelmente aconteceu pelo fato

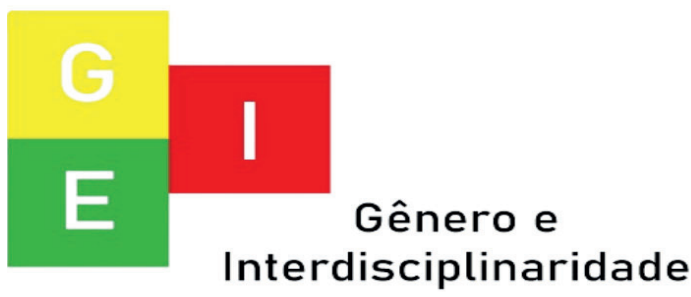


ISSN: 2675-7451

Vol. 03 - n 01 - ano 2022

Editora Acadêmica Periodicojs

de as crianças já conviverem durante a semana no PETI. Em seguida, o "nomear emoções", "consegue falar sentimentos", "usa locuções, como "por favor", "faz perguntas" e "expressa agrado", obteve uma alta freqüência, o que provavelmente é em função dos temas trabalhados e da escuta empática da facilitadora aos participantes.

O uso do Checklist facilitou bastante o trabalho de avaliação do processo, talvez pelo fato de sermos três pessoas, a estagiária, a supervisora de campo e uma outra psicóloga do PAIF.

Percebe-se que no comportamento "aluno grita e xinga o colega", houve uma discrepância entre a primeira e a décima primeira semana, que pode ser provocada pelo nível de estresse do monitor com a turma.

O presente estudo apresenta algumas limitações. Den- tre elas estão: (a) o espaço físico não adequado para intervenção, a sala continha vários objetos que dispersavam as crianças;

(b) o número de participantes foi grande, 13 crianças. Segundo Oaklander (1980) o trabalho com crianças nesta faixa etária deve ser de seis a dez crianças; (c) a aplicação do Questionário nos pais para avaliar as modificações e efeitos da intervenção no comportamento dos filhos, foram entrevistados apenas dois casais, três mães e um pai, ou seja, um total menor que $50 \%$, limitando a capacidade de generalização do trabalho; (d) a não adesão dos pais à intervenção para satisfação do objetivo proposto; (e) a replicação do Roteiro de entrevista com pais, seis meses após o fim do programa para verificar a efetividade do mesmo. Considera-se que o estudo contribuiu para replicação e

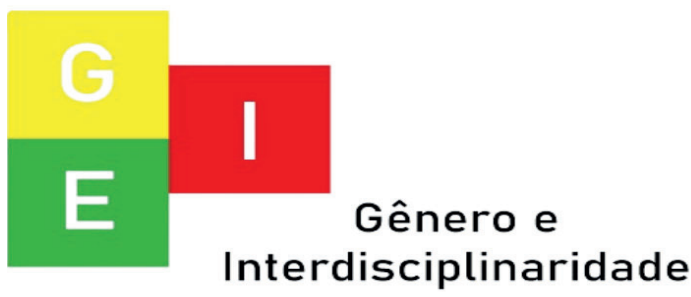


Vol. 03 - n 01 - ano 2022

Editora Acadêmica Periodicojs

pesquisa em prevenção de saúde em crianças, uma vez que expõe seu resultado positivo, objetivos, técnicas e instrumentos de avaliação do programa.

É relevante considerar em estudos futuros um trabalho conjugado entre pais e filhos (Baraldi \& Silvares, 2003), ou ao menos aos professores dessas crianças, capacitando-os para agirem como rede de apoio.

\section{Referências}

Baraldi, D. M., \& Silvares, E. F. de M. (2003). Treino de habilidades sociais em grupo com crianças agresivas, asociado à orientação dos pais: Análise empírica de uma proposta de atendimento. Em A. Del Prette \& Z. A. P. Del Prette (Orgs.), Habilidades sociais, desenvolvimento e aprendizagem: Quesotões conceituais, avaliação e intervenção (pp. 235-
258). Campinas: Alínea.

Bolsoni-Silva, A. T., \& Marturano, E. M. (2002). Práticas educativas e problemas de comportamento: uma análise à luz das habilidades sociais. Estudos de Psicologia, 7, n. 2, 227-235.

Caballo, V. E. (1997). El papel de las habilidades sociales em el desarrolo de las relaciones interpesonales. Em D. R. Zamignani (Org.), Sobre comportamento e cognição (pp 229-233). São Paulo: Arbytes.

Caballo, V. E. (2003). Manual de avaliação e treinamento das habilidades sociais. São Paulo: Santos.

Coie, J. D., Dodge, K. A., \& Coppotelli, H. (1982). Dimensions and types of social status: a cross-age perspective. Developmen-

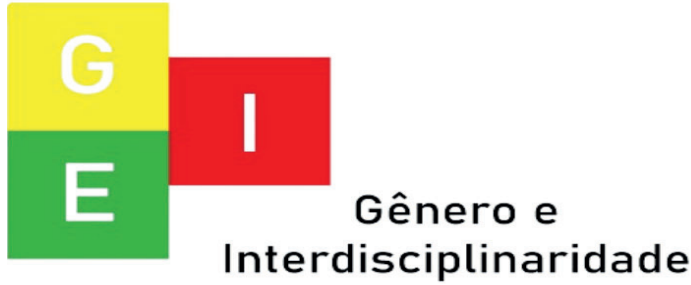


tal Psychology, 18,557-570.

D'Avila-Bacarji, K. M. G., Marturano, E. M., \& Elias, L. C. S. (2005). Suporte parental: um estudo com queixas escolares. Psicologia em Estudo, 10, n. 1, 107115.

Dell'aglio, D. D., \& Hutz, C. S. (2004). Depressão e Desempenho Escolar em Crianças e Adolescentes Institucionalizados. Psicologia: Reflexão e Crítica, 17, n. $3,341-350$.

De Antoni, C., \& Koller, S. H. (2001). O psicólogo ecológico no contexto institucional: Uma experiência com meninas vítimas de violência. Revista Psicologia: Ciência e Profissão, 21, n. 1, 1429.

Del Prette, Z. A. P., \& Del Prette, Ferreira, M. de C. T., \& MartuA. (1999). Psicologia das Habili- rano, E. M. (2002). Ambiente dades Sociais: Terapia e Educa-

ção. Petrópolis: Vozes.

Del Prette, Z. A. P., \& Del Prette, A.(2003). Aprendizagem socioemocional na infancia e prevenção da violência. Em A. Del Prette \& Z. A. P. Del Prette (Orgs.), Habilidades Sociais: DesenvolvimenDel Prette, Z. A. P., \& Del Prette, A. (2005). SMHSC - Sistema Multimídia de Habilidades Sociais de Crianças. São Paulo: Casa do Psicologo. Caderno de Pranchas.

Del Prette, Z. A. P., \& Del Prette A. (2006). Psicologia das Habilidades Sociais na infância: Teoria e Prática. Petrópolis: Vozes. 
Vol. 03 - n 01 - ano 2022

Editora Acadêmica Periodicojs

Familiar e os Problemas do Com- Melillo, E. N. S. Ojeda e Cols portamento apresentados por (Orgs.), Resiliência: descobrindo Crianças com Baixo Desempe- as próprias fortalezas (pp. 23-38). nho Escolar. Psicologia: Reflexão Porto Alegre: Artmed.

e Crítica, 20, n. 1, 34-44.

Magalhães, P. P. (2002). Treina-

Gomide, P. I. C. (2004). Pais mento de habilidades sociais com Presentes, pais ausentes: regras estudantes de Psicologia. e limites. Petrópolis: Vozes. Gorayeb, R. (2006). Ensino de Habilidades de Vida na Escola: Uma (2005). Panorama Geral dos Experiência com Adolescentes. Transtornos Infantis. Em V. E. Psicologia em Estudo, 11, n. 3, $561-568$.

Caballo \& M. A. Simón (Orgs.), Manual de Psicología Clínica Infantil e do Adolescente (pp. 29Grotberg, E. H. (2005). Introdu56). São Paulo: Santos.

ção: novas tendências em resiliência. Em A. Melillo, E. N. S. Ministério do Desenvolvimento Ojeda e Cols (Orgs.), Resiliência: Social e Combate à Fome. Prodescobrindo as próprias forta- grama de Erradicação do Tralezas (pp. 15-22). Porto Alegre: balho Infantil. Retirado no dia Artmed.

06/12/2007, do website http:// www.mds.gov.br/programas/ Infante, F. (2005). A Resiliência rede-suas/protecao-social-espeComo Processo: Uma Revisão cial/programa-de- erradicacaoda Literatura Recente. Em A. -do-trabalho-infantil-peti.

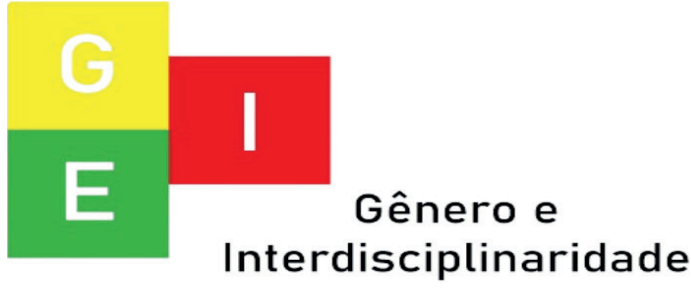


Risco e Proteção: Em busca de

Murta, S. G. (2007). Programas de Prevenção a Problemas Emocionais e comportamentais em Crianças e Adolescentes: Lições de três décadas de Pesquisa. Psicologia: Reflexão e Crítica, 20, n.1, 01-08.

Murta, S. G. (2008). Programa de Habilidades de Vida para Adolescentes: um manual para aplicação. Goiânia: Porã Cultural.

Oaklander, V. (1980). Descobrindo crianças: a abordagem gestáltica com crianças e adolescentes. São Paulo: Summus.

Papalia, D. E., \& Olds, S. W. (2000). Desenvolvimento Humano. Porto Alegre: Artes Médicas Sul.

Pesce, R. P., Assis, S. G., Santos, N. \& Oliveira, R. de V. C. (2004). um equilibrio promotor de Resiliência. Psicologia: Teoria e Pesquisa, 20, n. 2, 135-143.

Sapienza, G., Pedromônico, M. R. M. (2005). Risco, Proteção e Resiliência no desenvolvimento da criança e do adolescente. Psicologia em Estudo, 10 , n.2, 209216.

Sebastiani, R. W. (2004). O adolescente em situação de risco social: uma intervenção para promoção de saúde. Dissertação de Mestrado Não-Publicada, Programa de Pós- Graduação em Saúde Pública, Universidade de

Secretaria Nacional de Assistência Social (2005). Guia de Orientação Técnica SUAS no 1 Proteção Social Básica de Assistência Social. Brasilia - DF. Texto não

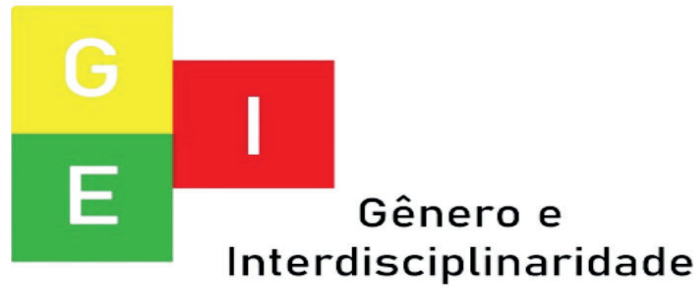


Vol. 03 - n 01 - ano 2022

Editora Acadêmica Periodicojs

publicado. vidade. Campinas: Papirus.

Santos, L. C., \& Marturano, E. M. Weber, L. (2007). Eduque com (1999). Crianças com dificuldade carinho: para pais e filhos. Curide aprendizagem: um estudo de tiba: Juruá.

seguimento. Psicologia: Reflexão

e Crítica, 12, n. 2, 377-394.

Silva, M. de P. (2006, novembro).

Treinamento de Habilidades Sociais para adolescentes: uma experiência no Programa de Atenção Integral à Familia(PAIF). Trabalho apresentado no IV Congresso de Psicologia de La Salud - ALAPSA, Sao Paulo, SP.

Vaz, S. P. A. (2007). Promoção de Resiliência e Habilidades Sociais Entre Adolescentes.

Virgolim, A. M. R., Fleith, D. de S., \& Pereira, M. S. N. (1999). Toc,toc...plim, plim!: lidando com as emoções, brincando com o pensamento a través da criati-

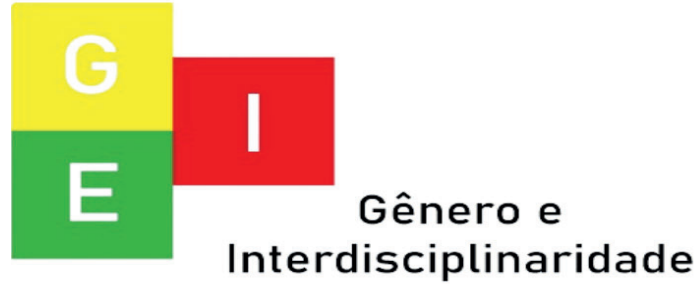

